\title{
How are the physical activity and anxiety levels of the university students affected during the coronavirus (Covid-19) pandemic?
}

Authors' Contribution: A Study Design

B Data Collection

C Statistical Analysis

D Data Interpretation

E Manuscript Preparation

F Literature Search

G Funds Collection

\author{
Zehra Güçhan Topcu ${ }^{1}$ ABCDEF, Beliz Belgen Kaygısız ${ }^{2}$ AEF, Cisel Demiralp ${ }^{1}$ AEF \\ ${ }^{1}$ Department of Physiotherapy and Rehabilitation, Faculty of Health Sciences, \\ Eastern Mediterranean University, Northern Cyprus, Mersin, Turkey \\ 2 Department of Physiotherapy and Rehabilitation, Faculty of Health Sciences, \\ European University of Lefke, Mersin, Turkey
}

\section{abstract}

Background: The Covid-19 pandemic has influenced all people's lives. The aim of this study was to evaluate the level of physical activity and anxiety of university students during the pandemic, and then determine some associated factors with anxiety of these young adults.

Material and methods:

A web-based questionnaire was sent to the participants. International Physical Activity QuestionnaireShort Form (IPAQ-SF) and Beck Anxiety Inventory (BAI) were used to collect data about the levels of their physical activity and anxiety.

Results: 247 participants (females $=151$, males $=96$ ) of the Faculty of Health Sciences whose mean ages were $21.46 \pm 2.1$ years old completed the study questions in 24 hours. The participants performed light physical activity according to the IPAQ-SF and had mild anxiety according to the BAl. Their gender, smoking status, and opinions on online education were found to be effective on the anxiety level $(p<0.05)$.

Conclusions: This paper indicated some important factors for the young adults who tried to continue their education in a very different way for a few weeks. Since this is not online education like past, both health professionals and university managements should consider the harms and risks of this new educational style on physical and psychological health of students before the upcoming semesters.

Key words: infectious disease, emotion, exercise, online education.

\section{article details}

Article statistics: Word count: 2,467; Tables: 2; Figures: 2; References: 15

Received: August 2020; Accepted: November 2020; Published: December 2020

Full-text PDF: http://www.balticsportscience.com

Copyright ๑ Gdansk University of Physical Education and Sport, Poland

Indexation: Celdes, Clarivate Analytics Emerging Sources Citation Index (ESCl), CNKI Scholar (China National Knowledge Infrastructure), CNPIEC, De Gruyter - IBR (International Bibliography of Reviews of Scholarly Literature in the Humanities and Social Sciences), De Gruyter - IBZ (International Bibliography of Periodical Literature in the Humanities and Social Sciences), DOAJ, EBSCO - Central \& Eastern European Academic Source, EBSCO - SPORTDiscus, EBSCO Discovery Service, Google Scholar, Index Copernicus, J-Gate, Naviga (Softweco, Primo Central (ExLibris), ProQuest - Family Health, ProQuest - Health \& Medical Complete, ProQuest - Illustrata: Health Sciences, ProQuest - Nursing \& Allied Health Source, Summon (Serials Solutions/ProQuest, TDOne (TDNet), Ulrich's Periodicals Directory/ulrichsweb, WorldCat (OCLC)

Funding: This research received no specific grant from any funding agency in the public, commercial, or not-for-profit sectors.

Conflict of interests: Corresponding author:

Open Access License:
Authors have declared that no competing interest exists.

Zehra Güçhan Topcu, PT., Assist. Prof. Eastern Mediterranean University, Faculty of Health Sciences, Department of Physiotherapy and Rehabilitation, Famagusta, Northern Cyprus, Mersin-10 Turkey; e-mail: zehra.guchan@emu.edu. tr, zehraguchan@hotmail.com; ORCID: 0000-0001-8587-7407

This is an open access article distributed under the terms of the Creative Commons Attribution-Non-Commercial-NoDerivatives 4.0 International (https://creativecommons.org/licenses/by-nc-nd/4.0/), which permits use, distribution and reproduction in any medium, provided the original work is properly cited, the use is non-commercial and is otherwise in compliance with the license. 


\section{INTRODUCTION}

In December 2019, novel coronavirus (COVID-19) radiated from Wuhan to other cities in China and since that time, has spread all around the World.1 It is a highly contagious disease and has no cure [1]. It has affected millions of people from all over the world $[1,2]$. On March 11, COVID-19 outbreak was declared as a pandemic by the World Health Organization (WHO). This situation has driven people into a state of great panic and fear. Moreover, another consequence of the disease is the confusion and anxiety among people, as there are many things which are still unknown about Covid-19 [1].

Before the pandemic, people devoted time to family, social life, academic life, etc. Additionally, people tried to follow the guideless of physical activity to sustain adequate health status and prevent chronic diseases, such as hypertension, diabetes, cardiovascular disease, respiratory diseases, sarcopenia and dementia [3-5]. However, today, according to the recommendations of the WHO, social isolation and self-quarantine are the best options to stop the spreading of the Covid-19 virus so daily physical activity is restricted at parks and sports areas in most of the countries. As a result of this radical change in lifestyles, various adverse effects on people's health seem inevitable [2].

Physical activity should be taken into account in order to decrease the harms of new lifestyles in these days. The importance of physical activity should be underlined for both physical and psychological benefits, and people should be informed about how they can increase the level of physical activity and what types of strategies can be developed at their homes $[3,6]$. Chen et al. gave several examples, such as chair squats and lifting groceries for physical activity at home [3]. Additionally, physical activity is beneficial for the immune system which is important, as a strong immune system may probably lower risk of contracting Covid-19 [7]. Research has consistently shown that physical activity reduces the risk of developing systemic inflammation [5]. Although high-quality studies are needed to confirm the effectiveness of exercise in prevention and prognosis of infection, clinical findings in adults have shown substantial declines in the days of symptoms after an infectious episode. Increased immune surveillance tends to be one of the principal mechanisms responsible for immune adaptations to physical activity [8, 9].

The lives have totally been different for all age groups including children, young adults, and the elderly. Both public and private sectors are trying to provide essential services. Education is one of these services. Due to the lock-downs, online education has started in all educational institutions from primary schools to universities. When compared with other age groups, university students have to spend more time on digital learning platforms, especially some faculties like faculty of health sciences have more intensive and long-hour courses in their curriculums. Since printouts could not be taken, these students had to stay on computer to listen the lectures and study the lecture notes for long times. They may also have many worries about their future lives. Thus, the aim of this study is to determine the level of physical activity and anxiety and to investigate which factors can have an impact on the anxiety level of the university students during the Covid-19 pandemic.

\section{MATERIAL AND METHODS}

This is a web-based cross-sectional study. An online software system was used to design an electronic web-based questionnaire to collect data.

\section{STUDY POPULATION}

The study participants included the undergraduate students whose age range was between 18 and 25 years old from the Department of Physiotherapy and Rehabilitation of two universities. They were invited to participate in the study from the online-education 
groups of two universities to which the authors are affiliated. The students came from the different cities of Turkey.

\section{DATA COLLECTION}

The data collection was conducted on 8-9 April 2020, and a 24-hour period was permitted for the study to cover the same period, as the questionnaires used questions related to the last 7 days. The total confirmed case number was seen as 38,226 in Turkey on this date.

Firstly, the participants were questioned whether they were volunteers or not, and volunteers continued to the questionnaire section. Age, gender, class, smoking status, whether their houses are with or without a garden, perception of the risk to get Covid-19 according to their cities, presence of Covid-19 positive cases in their environment, and the opinions about the effectiveness of online-education during the pandemic were recorded. A qualitative question was only used for the participants' opinions on the effectiveness of online education, and then it was grouped as positive, negative, and no comment.

Physical activity: The Turkish version of the International Physical Activity Questionnaire - Short Form (IPAQ-SF) was used to measure the level of the participants' physical activity [10]. This questionnaire includes questions about how people engage in vigorous and moderate physical activity by recording them in the number of days during the last 7 days and minutes per day. The daily total physical activity was calculated in MET-min-day and then grouped under three levels (light, moderate, and vigorous) [10].

Anxiety: The Turkish version of the Beck Anxiety Inventory (BAI) was used to measure the participants' anxiety level [11]. This inventory includes 21 items to rate the symptoms of anxiety with their intensities during the last 7 days. A four-point scale ranging from 0 (not at all) to 3 (severely - I could barely stand it) was used. Total BAI score ranges from 0 to 63, and higher scores show higher anxiety symptoms. Cut-off values were also used in the study to determine the anxiety level, as no anxiety is for $0-7$, mild anxiety is for 8-15, moderate anxiety is for 16-25, and severe anxiety is for 26-63 scores [11, 12].

\section{STATISTICAL ANALYSIS}

The data were analysed using the IBM Statistical Package for the Social Sciences (SPSS) 18.0. The qualitative findings were analysed as frequencies and percentages (\%). The quantitative findings were analysed as means and standard deviations. The ShapiroWilk test was used to analyse the distribution of the variables, and the data was not normally distributed. The Mann-Whitney U test was used for two continuous variables in two independent samples, and one-way ANOVA was used if there were more than two sample groups. When a significant difference was found, Tukey HSD (honestly significant difference) test, which is a Post Hoc test, was conducted to analyse the comparisons between two values. Pearson correlation was conducted to analyse the relationship between the levels of physical activity and anxiety. Difference at the $p<0.05$ level was considered to be statistically significant.

\section{RESULTS}

Out of the 295 questionnaires sent, 247 participants (male:96, female:151; mean age 21.46 \pm 2.1 years old) joined the study. Most participants (85.8\%) stated that they were with their parents, whereas about $15 \%$ of them apart from their parents (Table 1, Table 2). No participants had a positive Covid-19 result themselves or among their first degree relatives. 71.3\% participants stated that they did not smoke (Table 2). 
Table 1. Descriptive variables about age, physical activity, and anxiety

\begin{tabular}{cc} 
& Mean \pm SD \\
\hline Age (years) & $21.46 \pm 2.1$ \\
IPAQ-SF (light) & $446.99 \pm 804.66$ \\
IPAQ-SF (moderate) & $447.61 \pm 937.88$ \\
IPAQ-SF (vigorous) & $805.1 \pm 2774.36$ \\
IPAQ-SF (total) & $1593.79 \pm 2552.17$ \\
Sitting duration (min) & $330 \pm 351.67$ \\
Walking duration (min) & $18.18 \pm 26.05$ \\
BAI (total) & $9.4 \pm 8.76$ \\
\hline SD: Standard devion
\end{tabular}

SD: Standard deviation, IPAQ-SF: International Physical Activity Questionnaire-Short Form), BAI: Beck Anxiety Inventory

Table 2. Sociodemographic variables, levels of physical activity and differences between/among groups

\begin{tabular}{|c|c|c|c|c|}
\hline \multicolumn{2}{|c|}{ Variable } & N (\%) & BAl & $p$ \\
\hline \multirow{2}{*}{ Gender } & Women & $151(61.1)$ & $11.37 \pm 9.69$ & \multirow{2}{*}{$<0.001 *$} \\
\hline & Men & $96(38.9)$ & $6.31 \pm 5.91$ & \\
\hline \multirow{4}{*}{ Class } & I & $63(25.5)$ & $8.63 \pm 8.42$ & \multirow{4}{*}{0.234} \\
\hline & II & $79(32)$ & $9.54 \pm 8.12$ & \\
\hline & III & $60(24.3)$ & $11.17 \pm 9.32$ & \\
\hline & IV & 45 (18.2) & $7.89 \pm 9.41$ & \\
\hline \multirow{2}{*}{ Smoking status } & Non-smoker & $176(71.3)$ & $8.69 \pm 8.8$ & \multirow{2}{*}{$0.002 *$} \\
\hline & Smoker & $71(28.7)$ & $11.29 \pm 8.47$ & \\
\hline \multirow{3}{*}{ Perceived risk } & Low & $87(35.2)$ & $8.17 \pm 7.93$ & \multirow{3}{*}{0.187} \\
\hline & Medium & $118(47.8)$ & $9.73 \pm 9.42$ & \\
\hline & High & $42(17)$ & $11.05 \pm 8.33$ & \\
\hline \multirow[b]{2}{*}{ Living place } & Home with garden & $134(54.3)$ & $8.43 \pm 7.97$ & \multirow[b]{2}{*}{0.077} \\
\hline & $\begin{array}{l}\text { Apartment without } \\
\text { garden }\end{array}$ & $113(45.7)$ & $10.56 \pm 9.52$ & \\
\hline \multirow{3}{*}{$\begin{array}{l}\text { Opinions on online } \\
\text { education }\end{array}$} & Positive & $104(42.1)$ & $7.65 \pm 8.35$ & \multirow{3}{*}{$0.027 *$} \\
\hline & Negative & $122(49.4)$ & $10.7 \pm 8.7$ & \\
\hline & No comment & $21(8.5)$ & $10.57 \pm 10$ & \\
\hline \multirow{3}{*}{$\begin{array}{l}\text { Physical activity } \\
\text { (IPAQ-SF) }\end{array}$} & Light & $122(49.4)$ & $9.84 \pm 8.85$ & \multirow{3}{*}{0.489} \\
\hline & Moderate & $68(27.5)$ & $9.65 \pm 9.68$ & \\
\hline & Vigorous & $57(23.1)$ & $8.19 \pm 7.36$ & \\
\hline
\end{tabular}

N (\%): Number (Percentage) BAI: Beck Anxiety Inventory, IPAQ-SF: International Physical Activity Questionnaire-Short Form)

Regarding the perception of the risk of getting Covid-19 was asked, almost half of the participants reported medium-level risk for their living region, whereas $35.2 \%$ stated lowlevel and $17 \%$ stated high risk. $45.7 \%$ of the participants had home with a garden, while the rest of them lived in a flat. When the participants were asked about their opinions on the effectiveness of online education during the pandemic, almost half of them used positive statements, while half of them used negative, and $8.5 \%$ of them did not want to comment on this question (Table 2).

According to common positive opinions, they continued their education thanks to this system even in these conditions, whereas the issues like problems with concentration due to the feeling of the pandemic and hopelessness about the future, fear of getting Covid-19 by themselves or by their parents, problems with the Internet connection, reading from the screen for long hours due to the absence of print outs, ineffective processing of practical parts of the education, issues about online exams were stated as negative opinions. 
According to the IPAQ-SF results, $49.4 \%$ of the participants had light, $27.5 \%$ had moderate, and $23.1 \%$ had vigorous levels of physical activity (Table 2). The mean sitting duration was $330 \pm 351.67 \mathrm{~min}$, and mean walking duration was $18.18 \pm 26.05 \mathrm{~min}$. The mean score of the BAI was found to be $9.4 \pm 8.76$ PA so the participants had a mild level of anxiety (Table 1). According to the data presented in Table 2, males and fourth-class participants had no anxiety, while others had a mild level.

According to Table 2, results indicated that females had a significantly higher anxiety level than males $(\mathrm{p}<0.05)$. No significant difference was found between and among the classes I-IV ( $p>0.05)$. Students who smoked and had negative opinions on the effectiveness of online education had significantly higher anxiety level $(\mathrm{p}<0.05)$. No significant difference was found in the anxiety levels according to the living place and level of physical activity ( $p>0.05$ ) (Table 2, Figure 1). No significant correlation was found between the scores of BAI and IPAQ-SF results. $(r=-0.068, p=0.288)$.

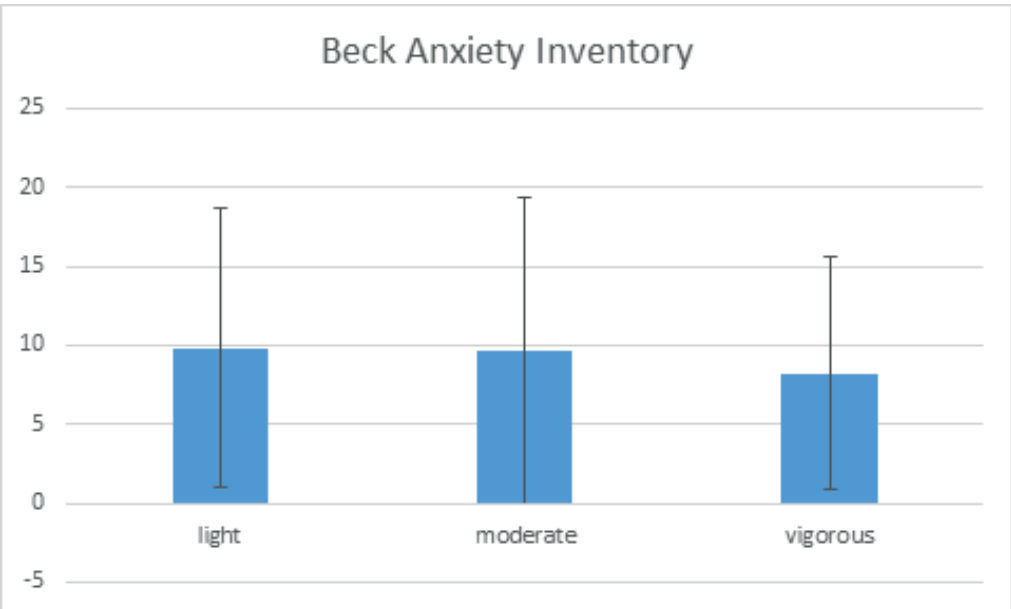

Fig. 1. Beck Anxiety Scores grouped as light, moderate, and vigorous IPAQ-SF levels

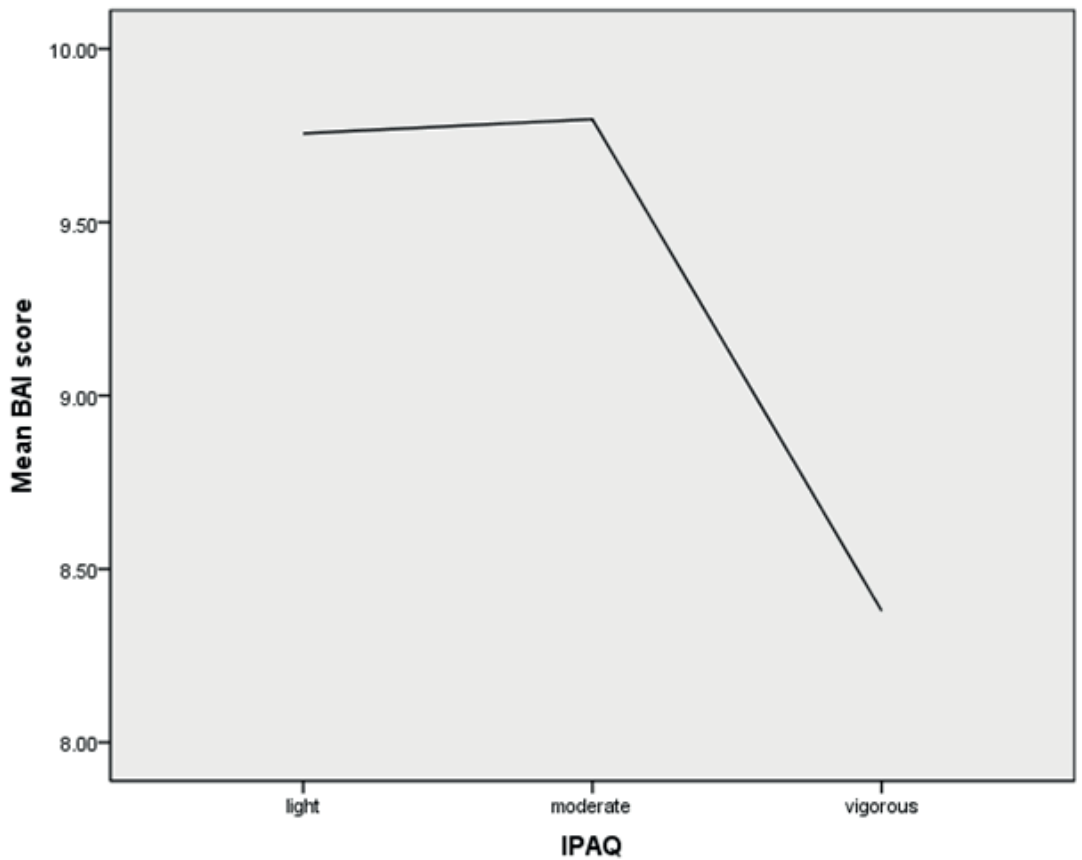

Fig. 2. The line of Beck Anxiety Scores according to light, moderate, and vigorous IPAQ-SF levels 


\section{DISCUSSION}

The novel coronavirus pandemic has caused a big change in the lifestyles all over the world. People from all age groups had to stay at homes for survival. The effects were similar in Northern Cyprus. All educational institutions of Northern Cyprus were closed with the first confirmed case on 9 March 2020. This paper showed that university students had different anxiety levels, depending on gender, smoking status, and perceptions about online education. However, class, living place and the level of physical activity (PA) were not found to be effective on their anxiety levels during the Covid-19 pandemic.

Female participants of the study had mild anxiety according to the BAI, while males had no anxiety. Thus, similarly to the study by Shevlin et al., females had a higher anxiety level than males during this time [13]. It does not show that females are under more stress related to getting Covid-19 more than males are; there are probably more factors to cause this difference between genders, like concerns about the future or financial problems. As regards the class of the students, no significant difference was determined among classes and the students of the fourth year who were going to graduate this semester, surprisingly, had no anxiety. The smoking status was found to be an effective factor in the anxiety level, and this may be related to Covid-19, as recent research has shown that both the progression and outcomes of the diseases were adversely affected by smoking [14]. As an unexpected result, there was no effect of the perception of the risk of getting Covid-19 on the participants' anxiety level, as even the people who reported a high risk for their regions manifested similar levels of anxiety to the people who reported a low risk. This may be caused by the low mortality rates in their age groups.

Considering the factors which can be related to student's pandemic days, their living places and online education were investigated. As the feeling of social isolations at homes may be worse for people who live in flats than for those who live at homes with gardens. This was the reason why the types of homes were also asked about in the questionnaire. However, this was not an effective factor to cause anxiety among the participants. According to the opinions about online education, the participants who found online education ineffective during this time had a higher anxiety level. This indicated that the students' psychological conditions were probably affected by the effectiveness of a new education style during the pandemic. The online education system was available at the universities before the pandemic, but this system was only used to upload files related to courses. Since the content of the courses included in the Physiotherapy and Rehabilitation curriculum were mostly practical, both lecturers and students had no experience in online lectures. Thus, it was difficult to do courses online as some students had no laptops and they tried to follow the courses from their phones for hours. Shortly, many factors may cause differences in anxiety levels according to opinions on online education.

Since students tried to continue their education in these conditions, this was not a surprised result that physical inactivity and sitting hours increased. Physical activity plays an important role in managing psychological problems and supporting the immune system $[6,7]$. Although the participants were physiotherapy students and could be more aware of the importance of physical activity, the findings showed that they had low levels of physical activity. Previously, they were trying to catch a bus, be at class on time, do shopping, go to social environments like cafes/cinemas, and using various opportunities of universities/ cities for exercise/sports like gym and park areas. Physiotherapy students were included in the study by Angin et al. [15], and IPAQ-SF was similarly used to determine the level of their physical activity. The most remarkable difference in the results can be seen in the sitting durations of students as they found its average as $28.7 \mathrm{~min}$, whereas this duration increased to $330 \mathrm{~min}$ with the pandemic days. Now, the students woke up and sat down in front of computer for online courses and even shopping was done by their parents. As 
a result, the level of their physical activity was low. Nevertheless, anxiety levels were not affected in the high levels of physical activity as no significant effects of different levels of physical activity were determined on anxiety level, and no correlation between physical activity and anxiety was found. Larger sample sizes and prospective study designs with addition of physical activity schedules to the program of students may help to increase the evidence and generalise these effects.

There are several limitations of this paper. First of all, this is a web-based study so a more valid instruments, like accelerometers, could not be used to measure physical activity. Secondly, other psychological measurements could contribute to presenting more results. However, as we are physiotherapists and we had a limited time for the study design, we wanted to use a test familiar to us. Further research can use different outcome measures. Thirdly, the time interval should be restricted to evaluate the effects of the pandemic in the same time, but this approach also limited making power analysis and finding the adequate sample size for the study design.

\section{CONCLUSION}

In conclusion, as the novel coronavirus pandemic has had a big impact on lifestyle of university students, educational activities to increase awareness about the physical activity level and to cope with anxiety should be conducted. New strategies should be improved for this new education style. For example, more intervals including postural exercises can be motivated at universities. More studies with larger sample sizes and different educational departments would help to compare students from different perspectives. This paper can also guide other studies related to the Covid-19 pandemic.

\section{REFERENCES}

[1] Wang C, Horby PW, Hayden FG, Gao GF. A novel coronavirus outbreak of global health concern. The Lancet. 2020; 395(10223):470-473. https://doi.org/10.1016/S0140-6736(20)30185-9

[2] Xiao H, Zhang Y, Kong D, Li S, Yang N. Social capital and sleep quality in individuals who self-isolated for 14 days during the coronavirus disease 2019 (COVID-19) outbreak in January 2020 in China. Med Sci Monit. 2020;26:e923921-1. https:// doi.org/10.12659/MSM.923921

[3] Chen P, Mao L, Nassis GP, Harmer P, Ainsworth BE, Li F. Coronavirus disease (COVID-19): The need to maintain regular physical activity while taking precautions. J Sport Health Sci. 2020;9(2):103-4. https://doi.org/10.1016/j. jshs.2020.02.001

[4] Ozemek C, Lavie CJ, Rognmo Ø. Global physical activity levels: need for intervention. Prog Cardiovasc Dis. 2019;62(2):102-107. https://doi.org/10.1016/j.pcad.2019.02.004

[5] Fletcher GF, Landolfo C, Niebauer J, Ozemek C, Arena R, Lavie CJ. Promoting physical activity and exercise: JACC Health Promotion Series. J Am Coll Cardiol. 2018;72(14):1622-1639. https://doi.org/10.1016/j.jacc.2018.08.2141

[6] Hammami A, Harrabi B, Mohr M, Krustrup P. Physical activity and coronavirus disease 2019 (COVID-19): Specific recommendations for home-based physical training. Manag Sport Leisure. 2020;1-6. https://doi.org/10.1080/2375 0472.2020.1757494

[7] Carter SJ, Baranauskas MN, Fly AD. Considerations for obesity, vitamin D, and physical activity amidst the COVID-19 pandemic. Obesity. 2020;28(7):1176-1177. https://doi.org/10.1002/oby.22838

[8] Nieman DC, Wentz LM. The compelling link between physical activity and the body's defence system. J Sport Health Sci. 2019;8:201-217. https://doi.org/10.1016/j.jshs.2018.09.009

[9] Laddu DR, Lavie CJ, Phillips SA, Arena R. Physical activity for immunity protection: Inoculating populations with healthy living medicine in preparation for the next pandemic. Prog Cardiovasc Dis. 2020; pii: S0033-0620(20)30078-5. https:// doi.org/10.1016/j.pcad.2020.04.006

[10] Saglam M, Arikan H, Savci S, et al. International physical activity questionnaire: Reliability and validity of the Turkish version. Percept Mot Skills. 2010;111(1):278-284. https://doi.org/10.2466/06.08.PMS.111.4.278-284

[11] Ulusoy M, Sahin N, Erkmen H. Turkish version of the Beck Anxiety Inventory: Psychometric properties. J Cogn Psychother. 1998;12:163-72. https://doi.org/10.2466/06.08.PMS.111.4.278-284

[12] Leyfer OT, Ruberg JL, Woodruff-Borden J. Examination of the utility of the Beck Anxiety Inventory and its factors as a screener for anxiety disorders. J Anxiety Disord. 2006;20(4):444-458. https://doi.org/10.1016/j.janxdis.2005.05.004

[13] Shevlin M, McBride O, Murphy J, et al. Anxiety, depression, traumatic stress, and COVID-19 related anxiety in the UK general population during the COVID-19 pandemic; 2020. https://doi.org/10.31234/osf.io/hb6nq 
[14] Vardavas CI, Nikitara K. COVID-19 and smoking: A systematic review of the evidence. Tob Induc Dis. 2020;18:20. https://doi.org/10.18332/tid/119324

[15] Angın E, Topçu ZG, Yatar İ, Depreli Ö, Tomaç H, Mıç̧ığlu S. Assessment of physical activity and academic success levels in physiotherapy and rehabilitation students. J Exerc Ther Rehabil. 2018;5(1):33-37. 